\title{
CXCL12 Retargeting of an Oncolytic Adenovirus Vector to the Chemokine CXCR4 and CXCR7 Receptors in Breast Cancer
}

\author{
Samia M. 0'Bryan' ${ }^{1}$ J. Michael Mathis ${ }^{1,2^{*}}$ \\ ${ }^{1}$ Department of Comparative Biomedical Sciences, School of Veterinary Medicine, Louisiana State University, Baton Rouge, LA, USA \\ ${ }^{2}$ University of North Texas Health Science Center, Graduate School of Biomedical Sciences, Fort Worth, TX, USA \\ Email: *michael.mathis@unthsc.edu
}

How to cite this paper: O'Bryan, S.M. and Mathis, J.M. (2021) CXCL12 Retargeting of an Oncolytic Adenovirus Vector to the Chemokine CXCR4 and CXCR7 Receptors in Breast Cancer. Journal of Cancer Therapy, 12, 311-336.

https://doi.org/10.4236/jct.2021.126029

Received: April 7, 2021

Accepted: June 5, 2021

Published: June 8, 2021

Copyright $\odot 2021$ by author(s) and Scientific Research Publishing Inc. This work is licensed under the Creative Commons Attribution International License (CC BY 4.0).

http://creativecommons.org/licenses/by/4.0/

\begin{abstract}
Breast cancer is the most frequently diagnosed cancer in women under 60 , and the second most diagnosed cancer in women over 60 . While significant progress has been made in developing targeted therapies for breast cancer, advanced breast cancer continues to have high mortality, with poor 5-year survival rates. Thus, current therapies are insufficient in treating advanced stages of breast cancer; new treatments are sorely needed to address the complexity of advanced-stage breast cancer. Oncolytic virotherapy has been explored as a therapeutic approach capable of systemic administration, targeting cancer cells, and sparing normal tissue. In particular, oncolytic adenoviruses have been exploited as viral vectors due to their ease of manipulation, production, and demonstrated clinical safety profile. In this study, we engineered an oncolytic adenovirus to target the chemokine receptors CXCR4 and CXCR7. The overexpression of CXCR4 and CXCR7 is implicated in the initiation, survival, progress, and metastasis of breast cancer. Both receptors bind to the ligand, CXCL12 (SDF-1), which has been identified to play a crucial role in the metastasis of breast cancer cells. This study incorporated a T4 fibritin protein fused to CXCL12 into the tail domain of an adenovirus fiber to retarget the vector to the CXCR4 and CXCR7 chemokine receptors. We showed that the modified virus targets and infects CXCR4- and CXCR7overexpressing breast cancer cells more efficiently than a wild-type control vector. In addition, the substitution of the wild-type fiber and knob with the modified chimeric fiber did not interfere with oncolytic capability. Overall, the results of this study demonstrate the feasibility of retargeting adenovirus vectors to chemokine receptor-positive tumors.
\end{abstract}

\section{Keywords}

Adenovirus, Breast Cancer, Cancer, Chemokine, CXCL12, CXCR4, CXCR7, 
Oncolytic, Preclinical, Receptor, Virotherapy, Virus

\section{Introduction}

Breast cancer remains the most commonly diagnosed cancer in women under 60 and second-most in women over 60 in the United States [1]. While significant progress has been made in developing targeted therapies for breast cancer, advanced breast cancer continues to have high mortality, with 5-year survival rates at $27 \%$ [1], thus highlighting the need for more efficient therapies. Specifically, new treatments are needed that can treat advanced and triple-negative breast cancer (TNBC). While a variety of targeted therapies are available for hormone receptor-positive breast cancers, especially at earlier stages, standard therapies such as chemotherapy and radiation remain the only choices for TNBC. Therefore, a more efficient therapy capable of targeting breast cancer cells while sparing normal tissue is sorely needed.

Adenoviruses have been investigated as therapeutic vectors in the context of breast cancer due to their natural ability to replicate in and lyse infected cells [2]. Adenoviruses are ideal therapeutic vectors due to being easy to manipulate, allowing for large transgene inserts and large-scale production. In addition, adenovirus vectors have been demonstrated to be clinically safe for local and systemic administration during oncolytic clinical trials [3] [4]. However, several characteristics of adenovirus vectors, including immunogenicity, liver sequestration, and low expression of the primary adenovirus receptor, CXADR or CAR, have limited their efficacy and have prevented their successful use in the clinic [5]. In recent years, the use of oncolytic adenovirus vectors in treating breast cancer has advanced to more sophisticated designs by incorporating tumor-specific promoters and transgene inserts [6] [7] [8] [9] [10], modifying fiber [11] and capsid proteins [12], and developing hybrid constructs [13]-[18].

Adenovirus vectors have been extensively explored in breast cancer treatment utilizing various targeting approaches and induction of therapeutic transgenes. A predominant approach to engineering recombinant adenovirus vectors has been to target cancer cells directly. Due to the downregulation of the endogenous adenovirus 5 (Ad5) receptor, the Coxsackie, and Adenovirus receptor (CXADR or CAR), there has been a search for alternative receptors that would mediate efficient viral entry [19]. Several oncolytic vectors have been designed to target alternative entry pathways through fiber and knob modifications. For example, replacing the Ad5 knob with the Ad3 knob retargets an oncolytic adenovirus to the CD46 receptor [20] and has been utilized extensively to target breast cancer cells [13] [15] [16] [17] [21]. In addition, breast cancer cells overexpressing the receptors HER3 and HER4 have been targeted with a fiber-modified oncolytic adenovirus utilizing the epidermal growth factor-like domain of heregulin- $\alpha$ (HRG) inserted into the HI loop of the Ad5 fiber [14]. The insertion of RGD-4C 
into the HI loop also allowed retargeting of an adenovirus to integrin adhesion receptors on breast cancer cells [22]. An adenovirus modified to incorporate a polylysine motif within the fiber retargeted the adenovirus to heparan sulfate proteoglycans (HSPGs) in breast cancer cells in vitro and in vivo [23].

In this study, we proposed targeting CXCR4, a G-protein coupled receptor (GPCR), one of the most commonly overexpressed chemokine receptors in cancer, including breast cancer [24]. CXCR4 functions as a mobilizer for hematopoietic stem cells and naïve lymphocytes and plays critical roles in the patterning of cell lineages during embryogenesis [25]. Currently, the only known ligand to CXCR4 is SDF-1, also known as CXCL12 [26]. In breast cancer cells, CXCR4 plays roles in the initiation, growth, progression, and, ultimately, the migration of tumor cells [27] and metastasis at distant sites [28] [29] [30]. In addition to CXCR4, a structurally related chemokine receptor, CXCR7, is capable of binding/sequestering SDF-1 [31]. CXCR7 is directly overexpressed in cancer cells [32], as well as in tumor-associated endothelial cells [33] and macrophages [34]. CXCR7 has also been implicated in driving tumor progression, e.g., tumor cell initiation, survival, progression, and metastasis [34] [35] [36]. Overall, the functional distribution of these receptors in breast tumors made them attractive targets for cancer therapy.

Previously, we successfully retargeted a replication-deficient Ad5 to CXCR4overexpressing breast cancer cells via a bi-specific adaptor molecule, sCARCXCL12 [37]. The sCAR-CXCL12 adapter resulted in the efficient retargeting of the adenovirus to CXCR4-overexpressing cancer cells. In addition, in a human ex vivo liver slice model, the virus complexed with the adapter reduced liver tissue infection [37]. Furthermore, the adenovirus injection complexed with sCARCXCL12 into a SCID-bg mouse model further demonstrated liver-off and tumor-on biodistribution, supporting the safety rationale behind the targeting scheme [37]. Nonetheless, there are also significant disadvantages of using bispecific proteins in targeting oncolytic viruses [38].

Therefore, in the current study, we engineered a modified oncolytic adenovirus serotype 5 (Ad5) to express the human chemokine ligand CXCL12 in the context of a T4 fibritin-modified fiber for use as a single-component targeting moiety. We investigated the efficacy of infection of this new vector in a panel of breast cancer cell lines and determined its oncolytic capability.

\section{Material and Methods}

\subsection{Cell Lines}

The characteristics of the human breast cancer cell lines described by Smith et al. [39] and used for the cytotoxicity assays are shown in Table 1. The human embryonic kidney cell line HEK293 and breast cancer cell lines BT-20, MCF-7, MDA-MB-231, MDA-MB-436, and ZR-75-1 were obtained from ATCC (Manassas, VA) and maintained in DMEM supplemented with 10\% FBS (Gemini, West Sacramento, CA), 1\% penicillin/streptomycin (Thermo Fisher, Waltham, 
Table 1. Classification and basic expression profile of a panel of normal and breast cancer cell lines.

\begin{tabular}{cccccccc}
\hline \multirow{2}{*}{ Cell Line } & Tumor Type & $\begin{array}{c}\text { Histological } \\
\text { Classification }\end{array}$ & $\begin{array}{c}\text { Molecular } \\
\text { Classification }\end{array}$ & \multicolumn{2}{c}{ Receptor Status } \\
\cline { 6 - 8 } MCF-12A & normal breast & $\begin{array}{c}\text { spontaneous } \\
\text { immortalization }\end{array}$ & normal epithelial & - & - & - \\
BT-20 & primary breast & Basal A & TNBC & - & - & + \\
MCF-7 & pleural effusion & Luminal A & ER+ & + & + & - \\
MDA-MB-231 & pleural effusion & Basal B & TNBC & - & - & - \\
MDA-MBA-436 & pleural effusion & Basal B & TNBC & - & - & - \\
ZR-75-1 & ductal carcinoma & Luminal A & ER+ & + & + & + \\
\hline
\end{tabular}

Abbreviations: TNBC, triple-negative breast cancer; ER, estrogen receptor; PR, progesterone receptor; HER2, human epidermal growth factor receptor 2.

MA) and 1\% NEAA (Thermo Fisher). The human mammary gland epithelial cell line, MCF-12A, was obtained from ATCC and maintained in DMEM/F12 containing $5 \%$ donor horse serum, $0.5 \mu \mathrm{g} / \mathrm{mL}$ hydrocortisone, $0.01 \mathrm{mg} / \mathrm{mL}$ bovine insulin, $100 \mathrm{ng} / \mathrm{mL}$ cholera toxin, and $20 \mathrm{ng} / \mathrm{mL}$ human EGF. The Chinese hamster ovary cell lines, $\mathrm{CHO}$ and CHO-CAR (stably expressing the CXADR or CAR cDNA) as characterized previously [40], were kindly provided by Rhonda Cardin (Louisiana State University School of Veterinary Medicine, Baton Rouge, LA) and maintained in RPMI 1640 (Genesee Scientific, San Diego, CA) containing 10\% FBS, $2 \mathrm{mM}$ L-glutamine, $1 \%$ penicillin/streptomycin, $10 \mu \mathrm{g} / \mathrm{mL}$ thymidine (Sigma-Aldrich, St. Louis, MO), $10 \mu \mathrm{g} / \mathrm{mL}$ adenosine (Sigma-Aldrich) and $10 \mu \mathrm{g} / \mathrm{mL}$ 2-deoxyadenosine (Sigma-Aldrich). CHO-CAR cells were also supplemented with $100 \mu \mathrm{g} / \mathrm{mL}$ Zeocin (InvivoGen, San Diego, CA). All cell lines were maintained at $37^{\circ} \mathrm{C}$ in a humidified $5 \% \mathrm{CO}_{2}$ atmosphere.

\subsection{CHO Cell Transfections}

Plasmid and cell line transfections were performed via Lipofectamine 3000 (Invitro-gen, Waltham, MA) according to the manufacturer's instructions. The CHO-CXCR4 cell line was established by transfection with a mammalian expression plasmid (pCMV6-AC-GFP; OriGene Technologies, Rockville, MD) containing the human CXCR4 transcript variant 1 cDNA sequence (NM_001008540) fused to a C-terminal tGFP tag. Similarly, the pCMV6-AC-GFP mammalian expression plasmid containing the human CXCR7 transcript cDNA sequence (NM_020311) fused to a C-terminal tGFP tag was used to establish the CHO-CXCR7 cell line. Transfected cells were incubated with transfection medium for 4 hours at $37^{\circ} \mathrm{C}$, after which the media was exchanged with fresh media. Stable transfectant cells were selected by using G418 sulfate at $800 \mathrm{mg} / \mathrm{ml}$. The CHO-CXCR4 and CHOCXCR7 were maintained in the same medium as the parental $\mathrm{CHO}$, with the addition of G418. All cell lines were maintained at $37^{\circ} \mathrm{C}$ in a humidified $5 \% \mathrm{CO}_{2}$ atmosphere. 


\subsection{Adenovirus Vector Construction}

We used a method described previously [41] [42] [43] to create a chimeric Ad5 fiber gene by genetic modification of the Ad fiber protein to contain a heterologous trimerization motif and a receptor-binding ligand. As shown in Table 2, sequences encoding the Ad5 fiber tail domain were fused to sequences encoding the bacteriophage T4 fibritin shaft and foldon domains, followed by sequences encoding the mature form of the CXCL12 protein. The Ad5 fiber, T4 fibritin, and CXCL12 sequences were separated by short peptide linkers; the total length of the construct was 1260 bp encoding 420 amino acids. In brief, a Srf I - Pac I Ad5 fragment containing the chimeric Ad5 fiber construct (5300 bp) was synthesized (GenScript, Piscataway, NJ) and used to replace the Srf I - Pac I fragment (5766 bp) of the wild-type Ad5 sequence (GenBank accession no. AY370909.2) within the pAdEasy-1 plasmid that lacks E1 and E3 (Agilent Technologies, Santa Clara, CA). Ampicillin-resistant colonies were selected following ligation and transformation; DNA was extracted, and identities of positive clones were confirmed by restriction digestion and polymerase chain reaction (PCR).

\subsection{Adenovirus Recombination}

To produce the fiber-modified adenovirus construct, we used an established recombination technique [44]. Using this technique, a shuttle plasmid containing the wild-type E1a and E1b genes, and the red fluorescent protein sequence fused to the minor capsid protein IX gene was co-transformed into the electrocompetent E. coli strain, BJ5183 (Agilent Technologies, Santa Clara, CA), with an Ad5 viral backbone plasmid containing the fiber-fibritin-CXCL12 insert. BJ5183 is a recombination proficient bacterial strain necessary to efficiently execute a recombination event between a shuttle plasmid and an adenovirus backbone plasmid. After recombination, Ad5-pIX-RFP-FF/CXCL12 (Ad5-ffCXCL12) recombinant colonies were selected on $100 \mu \mathrm{g} / \mathrm{mL}$ kanamycin agar plates incubated overnight in $37^{\circ} \mathrm{C}$ for a maximum of 16 hours. After incubation, the smallest colonies were chosen for amplification as these were most likely to contain recombinants. Colony amplification was conducted in $5 \mathrm{~mL}$ LB broth with $100 \mu \mathrm{g} / \mathrm{mL}$ Kanamycin overnight in a shaking incubator for a maximum of 16 hours. Following amplification, plasmids were extracted via miniprep (Bio-Rad, Hercules, CA) and analyzed via Hind III restriction enzyme digestion (New England Biolabs, Ipswich, MA) to screen for positive recombinants. Upon positive recombinant clone verification,

Table 2. GenBank DNA and amino acid sequences associated with the chimeric Ad5 fiber construct.

\begin{tabular}{cccc}
\hline fiber-fibritin-CXCL12 gene (ffCXCL12) & GenBank accession no. & Amino acid sequence & Nucleotide sequence (bp) \\
\hline Ad5 fiber N-terminus tail domain & MF681662.1 & amino acids 1-67 & $30997-31197(201)$ \\
Linker sequence & JF745946.1 & NGLSLDEAGNLT & $31361-31396(36)$ \\
T4 fibritin shaft and foldon domains & X12888.1 & amino acids 231 - 487 & $688-1461(774)$ \\
Linker sequence & LC498629.1 & GGGGSGGGGSGGGGS & $254-298(45)$ \\
Human CXCL12, transcript variant 1 & NM_199168.3 & amino acids 21 - 89 & $156-359(204)$ \\
\hline
\end{tabular}


clones were then analyzed via PCR for the E1A, pIX, Ad5-E4, and Ad5-penton genes. A clone was chosen that was positive for all genes and subsequently transduced into XL10-Gold ultracompetent E. coli cells (Agilent Technology, Santa Clara, CA). Colonies were grown on $100 \mu \mathrm{g} / \mathrm{mL}$ kanamycin plates overnight at $37^{\circ} \mathrm{C}$. The following day, a single colony was chosen and amplified further in XL10Gold ultracompetent cells using $400 \mathrm{~mL}$ of LB broth with $100 \mu \mathrm{g} / \mathrm{mL}$ Kanamycin. After incubation overnight in a shaking incubator at $37^{\circ} \mathrm{C}$, Ad5-ffCXCL12 was extracted using a maxiprep kit (Bio-Rad, Hercules, CA). The resulting DNA was then purified by phenol: $\mathrm{CHCl}_{3}$ extraction and $70 \%$ ethanol precipitation overnight at $-80^{\circ} \mathrm{C}$. The next day the precipitated DNA was ultracentrifuged at $13,000 \mathrm{rpm}$ for 30 minutes at $4^{\circ} \mathrm{C}$. The resulting plasmid stock was resuspended in ultrapure $\mathrm{H}_{2} \mathrm{O}$ and analyzed for concentration using a NanoDrop 8000 spectrophotometer (Thermo Fisher, Waltham, MA). The plasmid was confirmed to contain the E1a, pIX-RFP, CXCL12, and fiber-fibritin genes by PCR.

\subsection{Adenovirus Rescue}

To prepare the viral plasmid for transfection into the mammalian virus packaging cell line, HEK293-CXCR4, restriction enzyme digestion using Pac I (New England Biolabs) was used to linearize the plasmid. Following digestion, the plasmid was confirmed via gel-electrophoresis to confirm the presence of a small ligated portion of the viral plasmid, which confirms the linearization. The resulting linearized DNA was purified and concentrated via ethanol precipitation at $-20^{\circ} \mathrm{C}$. Purified viral DNA was then transfected using Lipofectamine 3000 reagent (Invitrogen, Waltham, MA) into HEK293-CXCR4 cells and incubated at $37^{\circ} \mathrm{C}$ for 7 to 14 days. Viral plasmid transfection was monitored for increasing fluorescence over the course of two weeks, after which potential virus was extracted in PBS from the cells via 3 freeze and thaw cycles using a dry ice bath. The resulting supernatant was then applied to a fresh dish of HEK293-CXCR4 cells at $60 \%$ confluency for viral rescue. The successful viral rescue was monitored via fluorescence microscopy until cells exhibited an extensive cytopathic effect and began to detach from the dish surface. Virus extraction was conducted via freeze/thaw cycles, and fresh HEK293-CXCR4 cells were infected for amplification. The virus was amplified to a maximum of sixty $150 \mathrm{~mm}$ dishes before harvesting for purification. The resulting virus supernatant (Ad5-ffCXCL12) was purified on a $\mathrm{CsCl}$ gradient, after which a titer was conducted via AdenoX Rapid Titer Kit (Clontech, Mountain View, CA). The control virus, Ad5-pIX-RFP-WT/ Fiber (Ad5-wtFiber), was amplified in HEK293 cells and purified via $\mathrm{CsCl}$ gradient centrifugation, after which titer was determined in the same manner as Ad5-ffCXCL12.

\subsection{PCR Analysis}

The designated primers (Table 3 ) were used to test the viral clone and resulting viral DNA, post-production, for the presence of essential genes (Invitrogen, Waltham, MA). Polymerase chain reactions (PCR) reactions were performed for 
Table 3. Primers sets for PCR analysis.

\begin{tabular}{ccc}
\hline Gene & Forward Primer & Reverse Primer \\
\hline Ad5-E4 & 5'-TCATGATTGCAAAAATTCAGGTTCC-3' & 5'-CTGTTGTAAGACAGGCTTCTAATGTTTA-3' \\
Ad5-penton & 5'-CGCGGCGATGTATGAGGAAGGT-3' & 5'-CCCGCGCCTTTAAACTTATTGG-3' \\
CXCL12 & 5'-CTGGCTTAAGAGCGAATG-3' & 5'-TCCACTTTAGCTTCGGGT-3' \\
Ad5-E1A & 5'-GCGGGAAAACTGAATAAGAG-3' & 5'-AGGCTCAGGTTCAGACACAG-3' \\
Fibritin & 5'-CGGCAACCTTACCCAGAA-3' & 5'-CGCCATCTTTACGAACGT-3' \\
Ad5-Fiber & 5'-ATGAAGCGCGCAAGACCGTC-3' & 5'-AGCTATGTGGTGGTGGGGCT-3' \\
pIX-RFP & 5'-GGAAGCATTGTGAGCTCATA-3' & 5'-TCTTGACCTCAGCGTCGTAGTGGCC-3' \\
\hline
\end{tabular}

Abbreviations: Ad5, adenovirus serotype 5; CXCL12, C-X-C Motif Chemokine Ligand 12; PCR, polymerase chain reaction; pIX, adenovirus protein IX; RFP, red fluorescent protein.

36 cycles at $94^{\circ} \mathrm{C}$ for 1 minute, $56^{\circ} \mathrm{C}$ for 30 seconds, and $72^{\circ} \mathrm{C}$ for 2 minutes.

\subsection{Immunoassays}

For detecting CXCL12 (SDF-1) protein on the adenovirus virions, serial dilutions of Ad5-wtFiber and Ad5-ffCXCL12 were examined using an SDF-1 alpha/CXCL12A Human ELISA Kit (Thermo Fisher) according to the manufacturer's instructions. Absorbance was read at $450 \mathrm{~nm}$ using a SpectraMax Plus microplate reader (Molecular Devices, Sunnyvale, CA). SDF-1 (CXCL12) levels were calculated using a standard curve generated from the kit.

\subsection{Western Blot Analysis}

For the preparation of whole-cell lysates, $1.2 \times 10^{6}$ cells per sample were collected and harvested with reducing Laemmli buffer followed by 5 minutes of boiling. Samples were run on $10 \%$ sodium dodecylsulfate-polyacrylamide gel electrophoresis (SDS-PAGE) gels and transferred to nitrocellulose membranes. Membranes were blocked for 1 hour with 5\% bovine serum albumin (BSA) and washed with TTBS (1\% Tween-20 in Tris-buffered saline). Afterward, the membranes were incubated with mouse monoclonal antibodies overnight at $4^{\circ} \mathrm{C}$. Membranes were analyzed for expression of CXADR (a.k.a. CAR or hCAR), CXCR4, and CXCR7, using primary antibodies PA5-31175, 35-8800, and PA5-28739, respectively (Thermo Fisher). Expression of $\beta$-actin was analyzed as a loading control using monoclonal antibody A1978 (Sigma-Aldrich). After three consecutive washes with TTBS, membranes were incubated with horseradish peroxidase-conjugated goat anti-mouse IgG antibody (Santa Cruz Biotechnology; Dallas, TX) for 1 hour and washed with TTBS. Finally, the membranes were developed using an enhanced chemiluminescent (ECL) reagent (GE Healthcare Biosciences, Pittsburgh, PA) for protein detection and visualized on a ChemiDoc imaging system (Bio-Rad).

\subsection{Cell Receptor Analysis}

The breast cancer cell lines were harvested with Versene and washed twice with 
cold PBS. Cells were incubated at $4^{\circ} \mathrm{C}$ for 30 minutes to 1 hour with PE-conjugated mouse anti-CXCR4 (FAB170P; R\&D Biosystems, Minneapolis, MN) mouse anti-CXCR7 (FAB42271P; R\&D Biosystems), or rabbit anti-CXADR (10799R271-P; Sino Biological Inc, Chesterbrook, PA). PE-conjugated mouse IgG2A antibody (IC003P; R\&D Biosystems) or monoclonal rabbit IgG (IC105P; R\&D Biosystems) were used as isotype controls. After incubation, the cells were washed twice in cold PBS, then resuspended in $0.5 \mathrm{~mL}$ ice-cold PBS and placed on ice. Analysis of receptor expression was conducted via flow cytometry using a FACSCalibur flow cytometer (BD Biosciences).

\subsection{Cell Lines}

Cells were seeded overnight into 24-well tissue culture plates at $1 \times 10^{5}$ cells/well. The next day, cells were infected with 2\% FBS DMEM media with Ad5-wtFiber or Ad5-ffCXCL12 at an increasing multiplicity of infection (MOI: 1, 10, 50, 100, 500 , and 1000). After incubation for 4 hours at $37^{\circ} \mathrm{C}$, virus-containing media was replaced with complete growth media and incubated at $37^{\circ} \mathrm{C}$ for 48 hours. At 48 hours, cells were harvested, washed with PBS, resuspended in $0.5 \mathrm{~mL}$ PBS, and analyzed by flow cytometry for the expression of the pIX-RFP protein.

\subsection{Cell Viability Assay}

Cells were plated at $1 \times 10^{4}$ cells per well into 96-well tissue culture plates. Cells were infected with the virus in $100 \mu \mathrm{L} 2 \%$ FBS DMEM media. Infected cells were incubated at $37^{\circ} \mathrm{C}$ for 72 to 96 hours. Cell viability post-infection was measured using an XTT cell viability kit (Cell Signaling Technology, Danvers, MA) at 72 and 96 hours. Absorbance was read at $450 \mathrm{~nm}$ using a SpectraMax Plus microplate reader (Molecular De-vices).

\subsection{2. siRNA Knockdown}

CHO-CXCR4 cells were transfected with 45nM CXCR4 siRNA (Dharmacon, Lafayette, $\mathrm{CO}$ ) at $37^{\circ} \mathrm{C}$ for 72 hours in transfection media according to the manufacturer's instructions. To confirm knockdown of CXCR4, the cells were harvested with Versene, imunostained using a PE-conjugated anti-CXCR4 antibody or a PE-conjugated isotype control antibody, and analyzed by flow cytometry. The cells were also analyzed for fluorescence detection of the CXCR4-tGFP fusion protein.

\subsection{Virus Binding Assay}

A qPCR-based method was used to assess the effect of CXCR4 knockdown on adenovirus virion binding to the cell surface. In this assay, untransfected $\mathrm{CHO}-$ CXCR 4 cells or cells transfected with 45 nM CXCR4 siRNA were harvested with Versene, washed once with ice-cold PBS, and incubated with 100 MOI Ad5wtFiber or Ad5-ffCXCL12 for 30 minutes on ice. Afterward, the cells were gently washed $3 \times$ with ice-cold PBS, pelleted by centrifugation, and resuspended in 
PBS. Total DNA was extracted from the cell samples using a QIAmp DNA mini kit (Qiagen; Germantown, MD) using the manufacturer's instructions. The extracted DNA was quantified using a NanoDrop 8000 spectrophotometer (Thermo Fisher), and $25 \mathrm{ng}$ of extracted DNA was used for real-time quantitative PCR (qPCR) to measure adenovirus E4 copy number. For qPCR of adenovirus E4 DNA, the following sets of primers and probes were synthesized (Thermo Fisher) and used: forward primer (5'-GGGTCGCCACTTAATCTACCT-3'); reverse primer (5'-GCAAGGCGCTGTATCCAA-3'); and probe (5'-FAM-

CGCTTGTGGTATGATGGCCACGT-TAMRA-3'). The following primers and probes were used to measure human GAPDH gene copy number: forward primer (5'-ACCAGGTGGTCTCCTCTGAC-3'); reverse primer (5'-

TTGCTGTAGCCAAATTCGTT-3'); and probe (5'-FAM-

TTTGTCAAGCTCATTTCCTGGTATGAC-TAMRA-3'). In this assay, the extracted DNA samples were amplified for 40 cycles at $94^{\circ} \mathrm{C}$ for 5 seconds and $60^{\circ} \mathrm{C}$ for 30 seconds, using a TaqMan Real-Time PCR Master Mix (Thermo Fisher Scientific) with the primers and probe on an Applied Biosystems 7900HT system (Thermo Fisher Scientific).

\subsection{Statistics}

Data are presenting as mean \pm standard deviation (S.D.). Single comparative data were analyzed for significance by the Student's t-test using GraphPad Prism 8.0 software (GraphPad Software; La Jolla, CA). Two-way ANOVA followed by Bonferroni's multiple comparisons test was performed to compare the percent cell survival or percent infected parameters at different MOI using GraphPad Prism 8.0 software.

\section{Results}

\subsection{Ad5-ffCXCL12 Characterization}

After the shuttle and backbone plasmids were transduced into electrocompetent $E$. coli cells, the smallest colonies were selected for miniprep plasmid extraction. As shown in Figure 1(A), plasmid DNA samples isolated from 10 different clones digested with the restriction enzyme Hind III showed a characteristic pattern, which was diagnostic of adenovirus genomes successfully recombined. After recombinant clone selection, PCR was performed on the clones $(5,6$, and 7) to further demonstrate the presence of key adenovirus genes: E1A, pIX, Ad5-E4, and Ad5-penton (Figure 1(B)). Based on these results, we identified clone 7 as a positive recombinant clone containing the screened genes. Clone 7 DNA was transduced into ultracompetent $E$. coli cells and amplified. After amplification, plasmid DNA was extracted, and PCR confirmed the presence of the modified fiber and CXCL12 insertion (Figure $1(C)$ ). After transfection, production, and purification of the viral stocks for Ad5-wtFiber and Ad5-ffCXCL12, PCR on Ad5-ffCXCL12 viral stock confirmed the presence of the T4 fibritin and CXCL12 genes (Figure $1(D)$ ). An ELISA for CXCL12 protein expression confirmed 

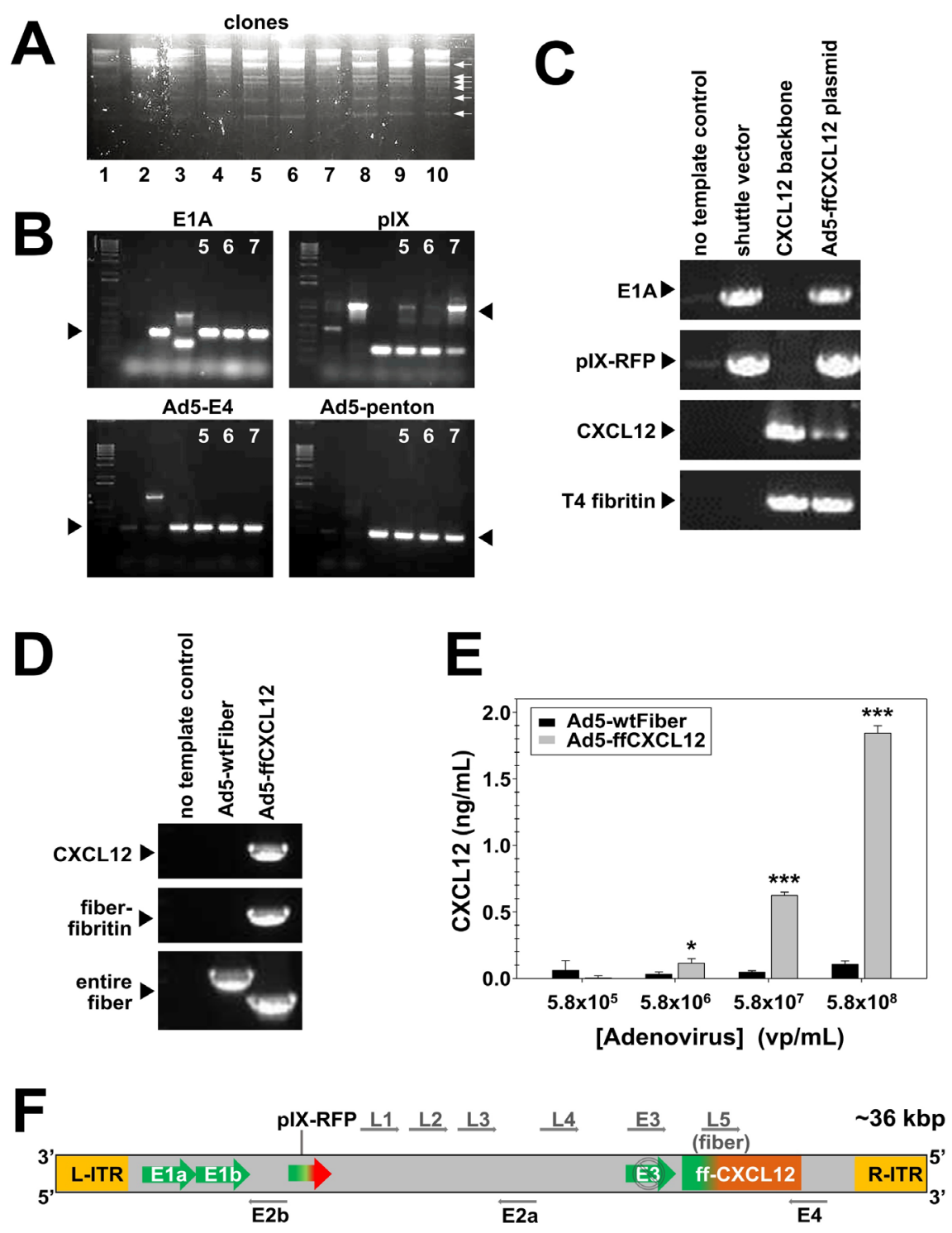

Figure 1. Recombinant adenovirus clone confirmation. (A) DNA isolated from potential recombinant clones digested with Hind III. (B) Clones 5, 6, and 7 screened for E1A, pIX, Ad5-E4, and Ad5-penton by PCR. (C) PCR analysis of recombinant plasmid DNA from clone 7 by PCR. (D) PCR analysis of final virus stock after amplification in 293A-CXCR4 cell line and purification with $\mathrm{CsCl}$ gradient. (E) ELISA analysis of CXCL12 protein expression in purified viral stock. Bars are representative of mean values \pm S.D. The differences between the two virus constructs at each adenovirus concentration were compared using Student's t-test and were considered statistically significant if $\mathrm{p}<0.05$; ${ }^{\star} \mathrm{p}<0.05$, ${ }^{* *} \mathrm{p}<0.001$. (F) Schematic of Ad5-ffCXCL12 genome. Abbreviations: VP, viral particles; $\mathrm{PCR}$, polymerase chain reaction; $\mathrm{CsCl}$, cesium chloride; S.D., standard deviation.

the CXCL12 ligand on the virus capsid (Figure 1(E)); the resulting design of the recombinant virus genome is depicted in Figure 1(F).

\subsection{Breast Cancer Cell Lines Express Varying Levels of CXCR4, CXCR7, and CXADR}

A panel of breast cancer cell lines (BT-20, MCF-7, MDA-MB-231, MDA-MB-436, 
and ZR-75-1) and the immortalized breast epithelial cell line, MCF-12A, were analyzed via flow cytometry for receptor expression. The data shown in Figure 2(A) indicate that the cell lines contain subpopulations expressing CXCR7 and CXADR at varying levels at the cell surface. CXCR4 expression was not detected in any of the cell lines via flow cytometry. However, western blot analysis of whole-cell lysate detected varying levels of CXCR4 expression (Figure 2(B)). The discrepancy between the two receptor identification methods may be due to endocytosis of the receptors upon antibody binding for flow cytometry or to the presence of intracellular CXCR4. CXCR7 was found in all cell lines as distinct populations of cells by flow cytometry, except in MDA-MB-436, where the cells express a more homogenous population (Figure 2(A)). Western blot confirmed the CXCR7 presence in most cell lines, with the highest expression observed in BT-20 cells (Figure 2(B)). Similarly, the endogenous Ad5 receptor, CXADR (a.k.a. CAR), was present at varying levels in all cell lines with high levels expressed on MCF-12A, MCF7, MDA-MB-231, and MDA-MB-436 (Figure 2(A)). Western blot of CXADR found similar receptor levels in most cell lines, with the highest expression detectable in MDA-MB-436 (Figure 2(B)). It is worth suggesting that the differences in expression levels between the two methods may lie in receptor detection capability by western blot (total expression) versus flow cytometry (cell surface expression).

\subsection{Ad5-ffCXCL12 Efficiently Targets and Enhances Infection Efficacy in Breast Cancer Cells}

As shown in Figure 3, breast cancer cell lines were infected for 72 hours with increasing MOI of either Ad5-wtFiber or Ad5-ffCXCL12. All breast cancer cell lines demonstrated a significantly greater infection with Ad5-ffCXCL12 than Ad5-wtFiber (Figures 3(A)-(F)). Even in the presence of high levels of CXADR, Ad5-ffCXCL12 demonstrated significantly enhanced infectivity compared with Ad5-wtFiber, as observed in both the MDA-MB-231 (Figure 3(D)) and the MDA-MB-436 (Figure 3(E)) cell lines. While the MDA-MB-231 cell line analysis indicated low CXCR4 and CXCR7 expression (Figure 2), there was no correlation with Ad5-ffCXCL12 infection efficiency. As shown in Figure 3(D), infection efficiency was the highest of all cell lines tested, reaching $77.3 \%$ at 1000 MOI. This result suggests that minimal levels of the CXCR4 and CXCR7 receptors may be sufficient to mediate the efficient uptake of the modified virus. The overall infection efficiency of the non-tumorigenic breast epithelial cell line, MCF-12A (moderate internal CXCR4, low membrane CXCR7, high membrane CXADR), with Ad5-ffCXCL12 was lowest compared with the breast cancer cell lines (Figure $3(C)$ ). Of note, even in the presence of high levels of CXADR, infection efficiency with Ad5-wtFiber did not correlate with the high CXADR expression suggesting that infection was not necessarily dependent on receptor abundance. For example, although we identified moderate levels of CXADR in MCF-7 cells (Figure 2), Ad5-wtFiber infection was largely ineffective (Figure 3(B)). Likewise, poor infection efficiency in MCF-12A by Ad5-wtFiber (Figure 3(C)) 

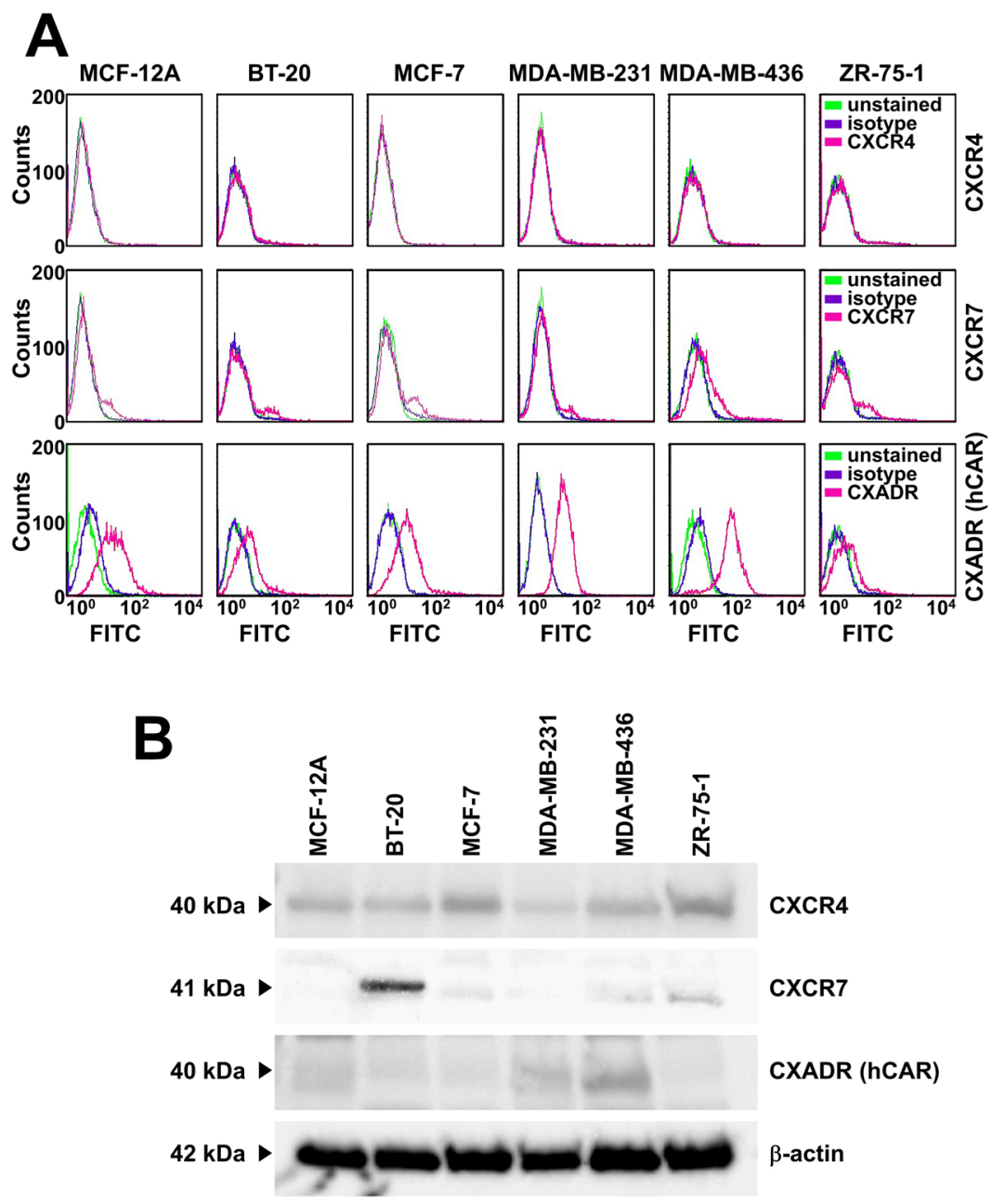

Figure 2. Expression of CXCR4 and CXCR7 in breast cancer cell lines. (A) Cell receptor expression was determined by flow cytometry of breast cancer cell lines immunostained with FITC-conjugated antibodies specific for CXCR4, CXCR7, and CXADR (a.k.a. CAR). Fluorescence detection of unstained cells (green peaks) was compared with cells immunostained with an isotype IgG staining (purple peaks) or a receptor-specific antibody (magenta peaks). In each experiment, 10,000 cells were analyzed for each sample. Shown are representative results of three independent experiments. (B) Western blot analysis of breast cancer cell lines. Aliquots of whole-cell lysates from each cell line were separated by SDS-PAGE, electroblotted onto nitrocellulose membranes, and probed with primary mouse anti-human antibodies specific for CXCR4 CXCR7, CXADR (a.k.a. CAR), or $\beta$-actin. Membranes were subsequently incubated with a horseradish peroxidase-conjugated goat anti-mouse IgG antibody, developed using an ECL reagent, visualized by a Western blotting imaging system. Shown are representative blots after visualization. Abbreviations: ECL, enhanced chemiluminescent; FITC, fluorescein isothiocyanate; SDS-PAGE, sodium dodecylsulfate-polyacrylamide gel electrophoresis.

may be due to the low expression of integrin $\alpha v \beta 3$ and $\alpha v \beta 5$ co-receptor expression [37].

\subsection{Ad5-wtFiber and Ad5-ffCXCL12 Exhibit Similar Oncolysis}

After the infection, cell viability was assessed at increasing MOI of either Ad5- 
A
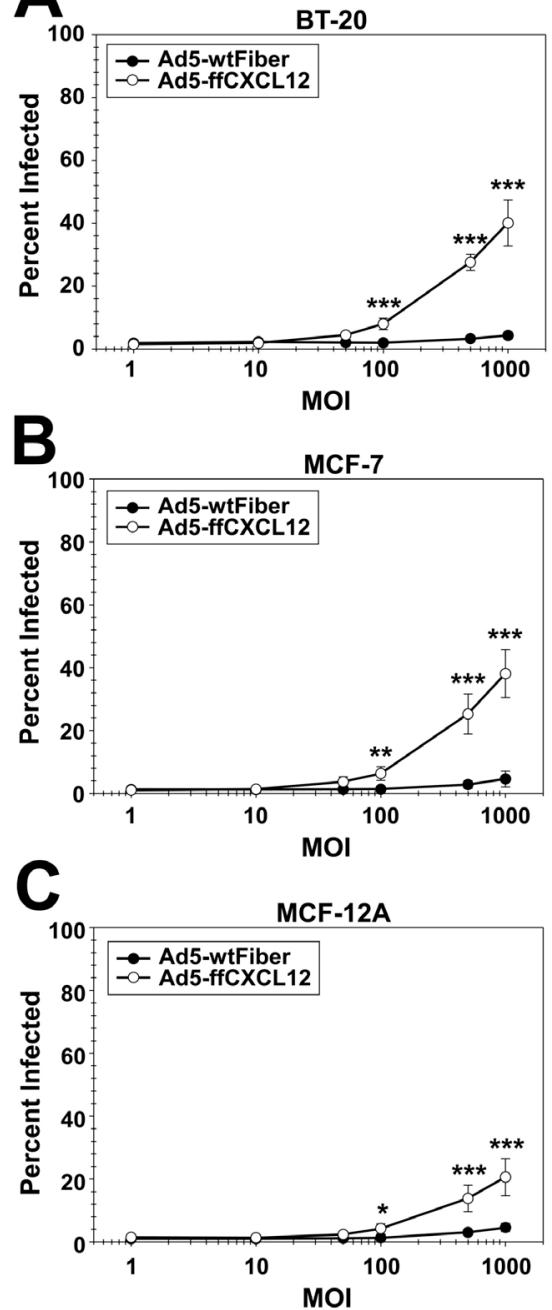

D

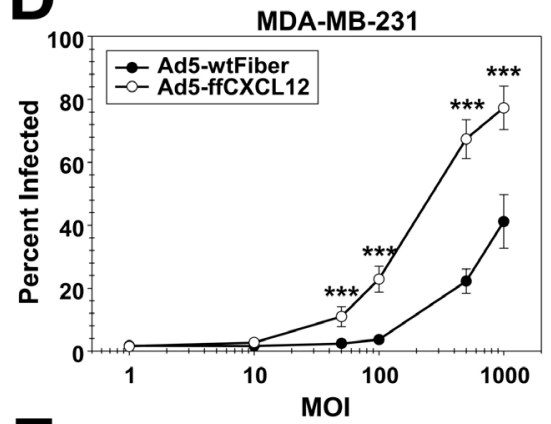

E

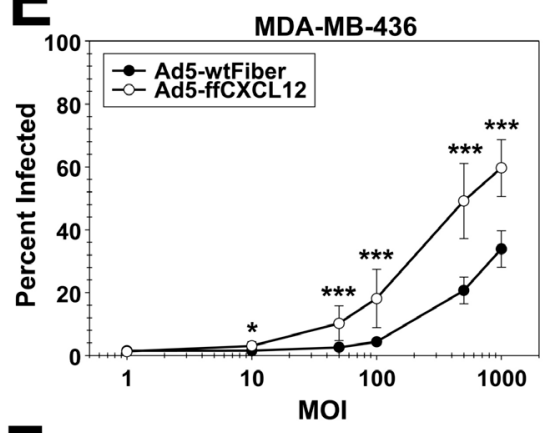

$\mathbf{F}$

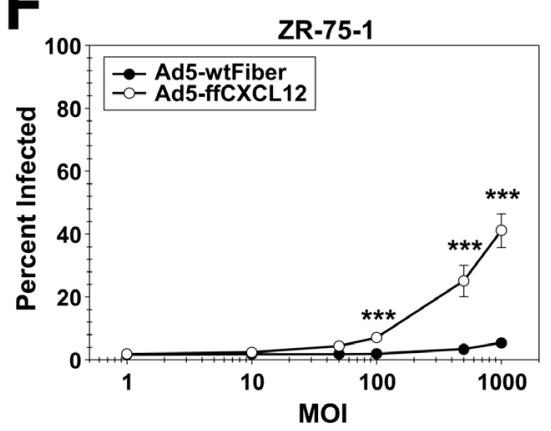

Figure 3. Detection of adenovirus infection. Percent of (A) BT-20, (B) MCF-7, (C) MCF-12A, (D) MDA-MB-231, (E) MDA-MB-436, and (F) ZR-75-1 cell lines infected with Ad5-wtFiber $(\bullet)$ or Ad5-ffCXCL12 $(O)$ after treatment for 72 hours with increasing MOI was determined by flow cytometry analysis of pIX-RFP expression. All data is representative of three replicate experiments. Points indicate the mean \pm S.D. of percent RFP positive cells. Two-way ANOVA followed by Bonferroni's multiple comparisons test was performed to compare the percent infected cells at each MOI. The differences between the two virus treatments at each MOI were considered statistically significant if $\mathrm{p}<0.05$; ${ }^{\star} \mathrm{p}<0.05,{ }^{*} \mathrm{p}<0.01,{ }^{* *} \mathrm{p}<0.001$. Abbreviations: MOI, multiplicity of infection; S.D., standard deviation.

wtFiber or Ad5-ffCXCL12 using an MTT assay. In this analysis, two different cell lines, MCF-12A and MDA-MB-436, were compared at 72 hours and 96 hours post-infection. Both cell lines expressed variable levels of CXCR7 and CXADR (Figure 2(A)). We show that cell viability of cells infected with Ad5-ffCXCL12 was comparable to viability after Ad5-wtFiber infection (Figure 4), suggesting that oncolytic efficiency is similar between the two viruses; the incorporation of the ff-CXCL12 does not hinder oncolytic efficiency. Overall, a decrease of cell viability at MOI 100 and 1000 were statistically significant $(\mathrm{p}<0.001)$ compared 
with that of uninfected cells. MCF-12A exhibits slighter decreases in cell survival between 72 and 96 hours (Figure 4(A) and Figure 4(B)); however, MDA-MB436 cells seemed more susceptible to both viruses at higher doses (Figure $4(\mathrm{C})$ and Figure 4(D)) when compared with MCF-12A. Growth inhibition of cells at these MOIs could be attributed to the direct oncolysis mediated by either virus's cytotoxic and bystander effects.

\subsection{Infection of Isogenic Cell Lines Engineered to Overexpress CXCR4, CXCR7, and CXADR}

To further investigate the role of different receptors in Ad5-ffCXCL12 infection, the CHO Chinese hamster ovary cell line was used to overexpress the human receptors CXADR, CXCR4, and CXCR7. Overexpression of CXCR4 (Figure 5(A)) and CXCR7 (Figure 5(B)) were assessed by flow cytometry utilizing a tGFP reporter gene fused to the receptor gene sequences. Further flow analysis was
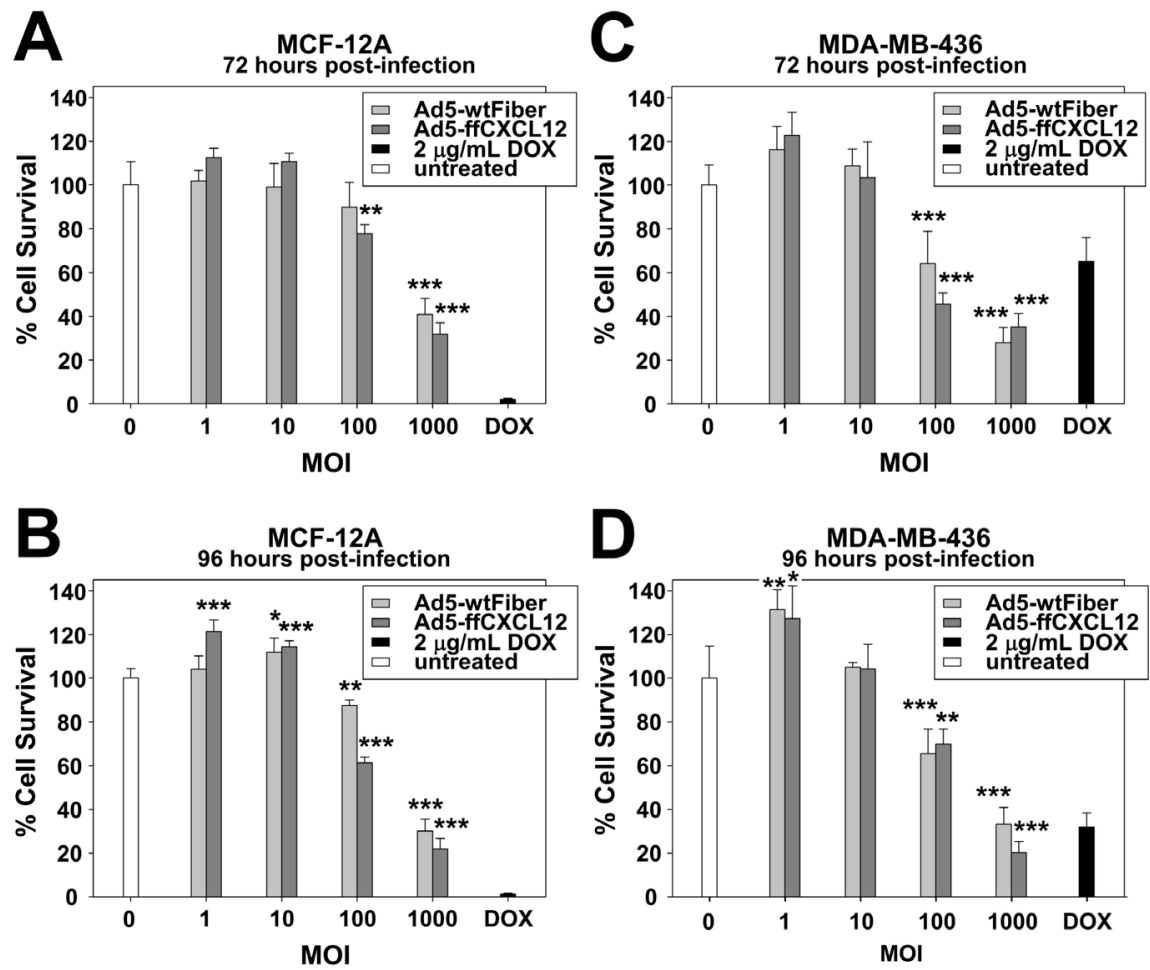

Figure 4. Viability assays of MCF-12A and MDA-MB-436 after infection with increasing MOI of Ad5-wtFiber or Ad5-ffCXCL12. MCF-12A cells were infected with increasing MOI of Ad5-wtFiber or Ad5-ffCXCL12 for (A) 72 hours or (B) 96 hours before XTT assays. MDA-MB-436 cells were also infected with increasing MOI of Ad5-wtFiber or Ad5-ffCXCL12 for (C) 72 hours or (D) 96 hours before XTT assays. As a positive control, the cells were treated $2 \mu \mathrm{g} / \mathrm{mL}$ DOX. All data are representative of five replicates normalized to untreated cells $(100 \%$ cell viability). Bars indicate the mean \pm S.D. Two-way ANOVA followed by Bonferroni's multiple comparisons test was performed to compare the percent cell survival at each MOI to uninfected cells (0 MOI). The differences between the virus treatment at each MOI and uninfected cells were considered statistically significant if $\mathrm{p}<0.05 ;{ }^{\star} \mathrm{p}<0.05,{ }^{* *} \mathrm{p}<0.01,{ }^{* *} \mathrm{p}<0.001$. Abbreviations: DOX, doxorubicin; MOI, multiplicity of infection; S.D., standard deviation. 


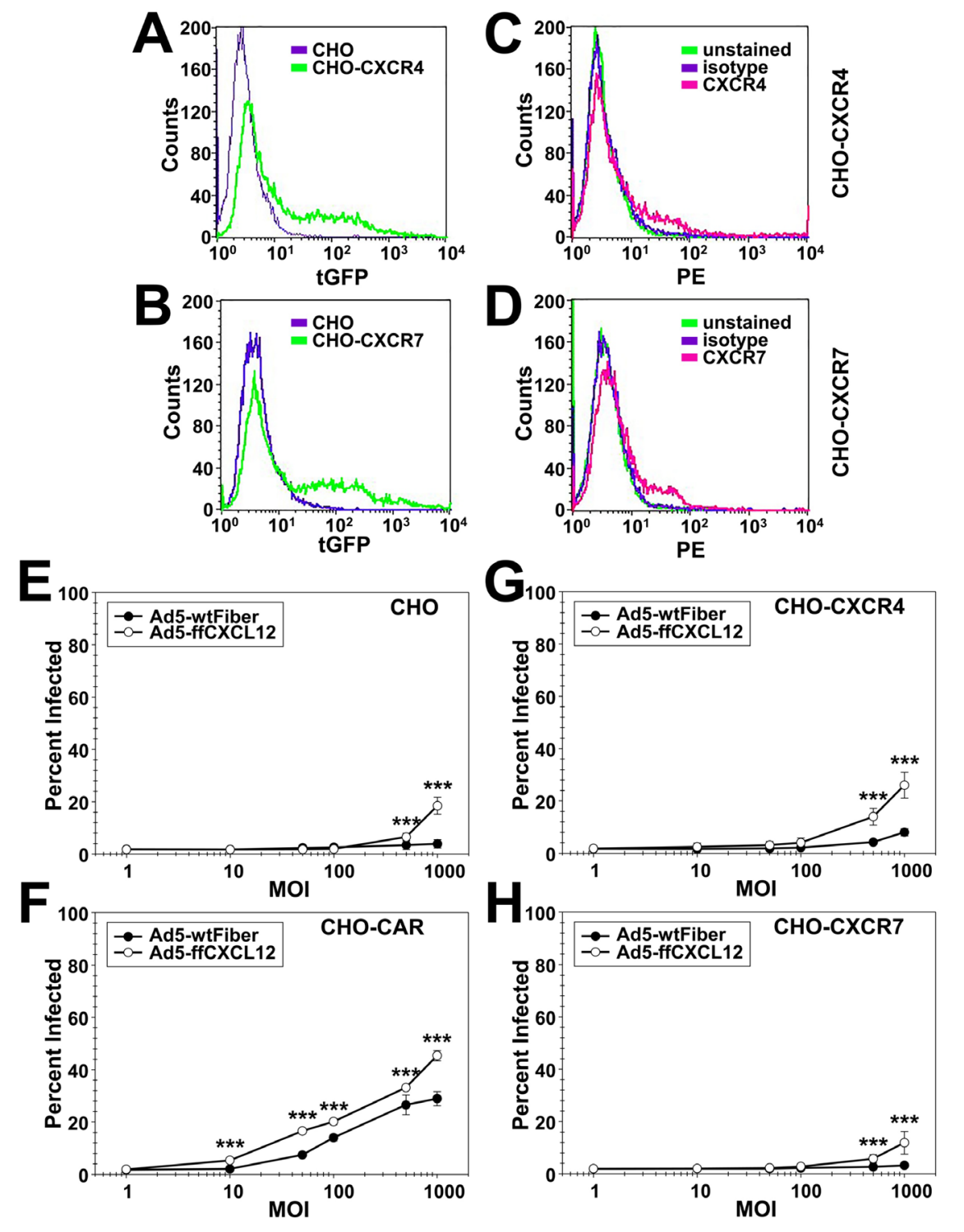

Figure 5. Expression of CXCR4 and CXCR7 in stably transfected CHO cells. GFP-tagged receptor expression in (A) $\mathrm{CHO}-\mathrm{CXCR} 4$ and (B) CHO-CXCR7 cells was compared to parental $\mathrm{CHO}$ cells by flow cytometry after stable transfection with mammalian expression plasmids. CHO-CXCR4 and CHO-CXCR7 cells were also examined by immunostaining for cell surface expression of (C) CXCR4 or (D) CXCR7 using PE-conjugated monoclonal antibodies specific for the human receptors. The cells were incubated with PBS alone (unstained), an isotype control antibody, or the receptor-specific antibody. Following incubation, the cells were washed, resuspended in $0.4 \mathrm{~mL}$ PBS, and analyzed by flow cytometry. The percent of (E) CHO, (F) CHO-CAR, (G) CHO-CXCR4, and (H) CHO-CXCR7 cell lines infected with Ad5-wtFiber (•) or Ad5-ffCXCL12 (O) for 72 hours at increasing MOI was determined by flow cytometry analysis of pIX-RFP expression. All data is representative of three replicate experiments. Points indicate the mean \pm S.D. of percent RFP positive cells. Two-way ANOVA followed by Bonferroni's multiple comparisons test was performed to compare the percent infected cells at each MOI. The differences between the two virus treatments at each MOI were considered statistically significant if $\mathrm{p}<0.05 ;{ }^{* * *} \mathrm{p}<0.001$. Abbreviation: MOI, multiplicity of infection; PE, phycoerythrin; RFP, red fluorescent protein; S.D., standard deviation; tGFP, turbo green fluorescent protein. 
conducted using antibodies targeting CXCR4 and CXCR7 (Figure 5(C) and Figure 5(D), magenta peaks). Of note, tGFP fusion protein expression was appeared higher than immune detection using anti-CXCR4 or anti-CXCR7 antibodies. This discrepancy could be attributed to the intracellular localization and trafficking of the CXCR4 and CXCR7 receptors from the cell surface. As expected, CHO parental cells were refractory to Ad5-wtFiber (Figure 5(E)) but were inherently susceptible to Ad5-ffCXCL12 infection (Figure 5(E)), with a statistically significant infection at 500 and 1000 MOI when compared with Ad5wtFiber. This modest increase in infected cells may be attributed to unknown hamster protein interactions with the modified fiber and knob, as Ad5-wtFiber could not infect $\mathrm{CHO}$ cells. As shown in Figure 5(F), overexpression of human CXADR in CHO-CAR cells was accompanied by an increased infection with Ad5wtFiber. In addition, CHO-CAR cells were also susceptible to Ad5-ffCXCL12 infection. In comparison, Ad5-ffCXCL12 infection was facilitated in CHO-CXCR4 (Figure 5(G)) and CHO-CXCR7 cells (Figure 5(H)). However, infection in both cell lines was lower than expected with Ad5-ffCXCL12. This result may suggest that additional factors may be necessary for efficient infection of adenovirus vectors in $\mathrm{CHO}$ cells.

\section{6. siRNA Knockdown of CXCR4 Diminishes Ad5-ffCXCL12 Binding}

CHO-CXCR4 cells were transfected with anti-CXCR4 siRNA. To determine the extent of CXCR4 expression, the cells were examined by two-parameter (dualcolor flow cytometry (Figure 6). In the CHO-CXCR4 cells, the CXCR4 cDNA was constructed to contain an N-terminal tGFP marker that allowed for fluorescence detection of total CXCR4 protein expression. The cells were also immunostained with a PE-labeled anti-CXCR4 antibody to assess cell surface expression of the CXCR4-tGFP fusion protein. As quantified in Table 4 and shown in Figure 6(A), flow cytometry analysis indicated approximately $14.1 \%$ of the untransfected CHO-CXCR4 cells were positive for tGFP-tagged CXCR4. Immunostaining with an anti-CXCR4 antibody revealed that approximately $10.1 \%$ of the GFP-positive cell population was positive for cell surface expression of CXCR4, while approximately 83.9\% was negative (Table 4 and Figure 6(B)).

Table 4. Quadrant analysis of CXCR4-tGFP fusion detection and PE-conjugated anti-human CXCR4 immunostaining of CHO-CXCR4 cells by flow cytometry.

\begin{tabular}{ccccc}
\hline & \multicolumn{2}{c}{ untransfected } & \multicolumn{2}{c}{ CXCR4 siRNA transfected } \\
\hline quadrant & isotype & anti-CXCR4 & isotype & anti-CXCR4 \\
\hline LL (tGFP- PE-) & $85.0 \%$ & $83.9 \%$ & $95.4 \%$ & $95.7 \%$ \\
UL (tGFP- PE+) & $0.1 \%$ & $0.4 \%$ & $0.1 \%$ & $0.1 \%$ \\
LR (tGFP+ PE-) & $14.1 \%$ & $10.1 \%$ & $4.0 \%$ & $3.4 \%$ \\
UR (tGFP+ PE+) & $0.8 \%$ & $5.6 \%$ & $0.5 \%$ & $0.8 \%$ \\
\hline
\end{tabular}

Abbreviations: LL, lower left; LR, lower right; UL, upper left; UR, upper right; PE, phycoerythrin tGFP, turbo green fluorescent protein. 

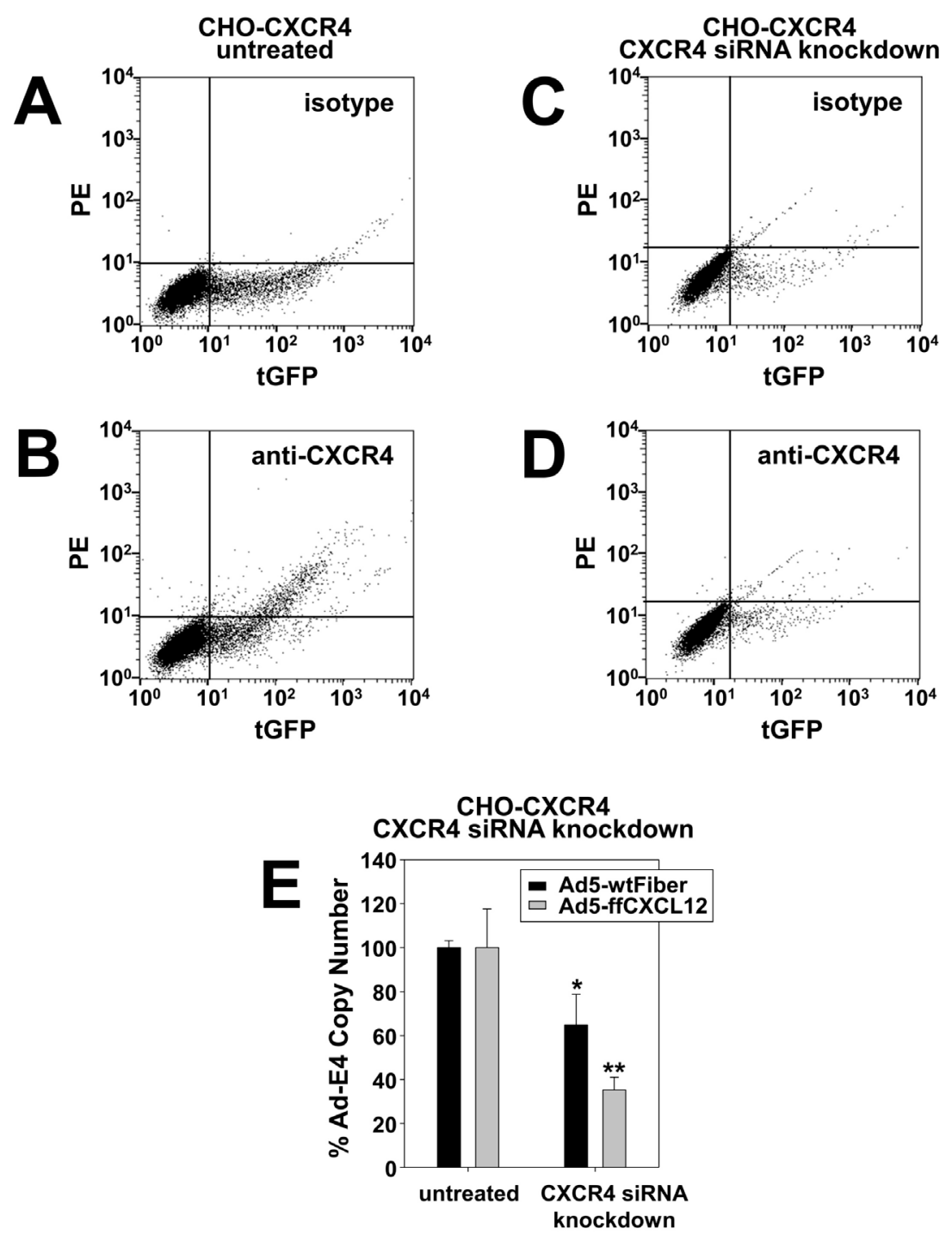

Figure 6. Effect of CXCR4 knockdown on adenovirus binding. Parental CHO-CXCR4 cells and CHO-CXCR4 cells transfected with CXCR4 siRNA were characterized by twoparameter (dual-color fluorescence) flow cytometry. Shown are representative fluorescence plots of tGFP-tagged receptor expression (x axis) and immunostaining of CXCR4 expression (y axis) in untransfected cells using an isotype control (A) or a PE-conjugated monoclonal antibody specific for the human receptor (B). CXCR4 expression was also determined in cells transfected for 72 hours with an anti-CXCR4 siRNA. Shown are representative fluorescence plots of tGFP-tagged receptor expression (x axis) and immunostaining of CXCR4 expression (y axis) in transfected cells using an isotype control (C) or a PE-conjugated monoclonal antibody specific for the human receptor (D). Binding of Ad5-wtFiber (black bars) or Ad5-ffCXCL12 (grey bars) at 100 MOI was determined by qPCR of DNA isolated from untransfected CHO-CXCR4 cells or CHO-CXCR4 cells transfected for 72 hours with an anti-CXCR4 siRNA (E). All data are representative of five replicates normalized to untransfected cells (100\% cell viability). Bars indicate the mean \pm S.D. The differences between the untransfected and transfected groups were compared using Student's t-test and were considered statistically significant if $\mathrm{p}<0.05$; ${ }^{*} \mathrm{p}$ $<0.05,{ }^{* *} \mathrm{p}<0.01$. Abbreviations: MOI, multiplicity of infection; PE, phycoerythrin; qPCR, quantitative polymerase chain reaction; S.D., standard deviation; siRNA, small interfering RNA; tGFP, turbo green fluorescent protein. 
These results are consistent with the process of internalization and recycling of GPCRs. Importantly, CXCR4 siRNA transfection of CHO-CXCR4 resulted in a decrease of tGFP-tagged CXCR4 (Table 4 and Figure 6(C)) to approximately $4 \%$ as determined at 72 hours post-siRNA transfection. Immunostaining with an anti-CXCR4 antibody showed that CXCR4 siRNA transfection resulted in similarly low levels of cell surface CXCR4 expression at 3.4\% (Table 4 and Figure 6(D)). The effect of CXCR4 knockdown was next investigated on Ad5-ffCXCL12 using a virus binding assay. After 72 hours of siRNA transfection, the CHO-CXCR4 cells were infected with $100 \mathrm{MOI}$ of either Ad5-wtFiber or Ad5-ffCXCL12 for 30 minutes. As shown in Figure 6(E), CXCR4 knockdown resulted in a decrease in Ad5-ffCXCL12 binding to $35 \%$ of control untransfected) cells. CXCR4 knockdown also decreased Ad5-wtFiber binding, although the effect was only at $65 \%$ of control (untransfected) cells.

\section{Discussion}

The wild-type receptor for Ad5, CXADR, is downregulated in the majority of breast tumors, limiting the therapeutic efficacy of wild-type fibered Ad5 vectors [45]. Thus, the present study sought to utilize this chemokine axis to retarget an oncolytic Ad5 to increase infection in breast cancer cells. The utility of retargeting Ad5 with fiber modifications has been shown to be a viable therapeutic approach [13] [14] [15] [16] [17] [21] [22] [23]. In this approach, the replacement of the Ad5 fiber-knob with T4 fibritin maintains the structural integrity of the Ad5 fiber and allows for larger ligand insertions into the knob domain [46] [47]. We previously utilized the T4 fibritin platform to successfully retarget an oncolytic adenovirus to the cMet receptor in hepatocellular carcinoma and breast cancer [48]. Ad5 binding is mediated by the CXADR receptor, and entry is facilitated in a two-step uptake mechanism by the $\alpha \mathrm{v} \beta 3$ and $\alpha \mathrm{v} \beta 5$ integrins as well as other integrins that recognize Arg-Gly-Asp (RGD) motif that is expressed on the penton base protein [49]. However, in the absence of CXADR, Ad5 binding has been shown to be mediated by a host of cell surface receptors. Heparan sulfate glycosaminoglycans have been found to act as fiber-independent and fiber-dependent binding receptors for Ad5 [50] [51]. The $\alpha v \beta 5$ integrin has also been shown to act as a primary receptor in the absence of CXADR [52]. Overall, Ad5ffCXCL12 infection of MCF-12A cells was lower than breast cancer cell lines, possibly attributable to low levels of $\alpha v \beta 3$ and $\alpha v \beta 5$ at the cell surface [37].

The therapeutic importance of targeting the CXCR4-CXCR7-CXCL12 axis in breast cancer has been widely recognized, in part due to the overexpression of both receptors occurring at different stages and subtypes of breast cancer [53] [54] [55] [56] [57]. In this study, we evaluated the efficacy of incorporating the CXCL12 ligand into the C-terminus of a modified fiber gene containing the Ad5 tail domain and the T4 fibritin shaft and foldon domains. We previously demonstrated the efficacy of retargeting a replication-deficient adenovirus to CXCR4 and CXCR7 using a bi-specific adaptor molecule [37]. The replication-deficient 
Ad5 was successfully retargeted to cancer cells overexpressing CXCR4 and detargeted the liver uptake in vivo. However, due to the bi-specific nature of the adaptor and unknown safety and pharmacokinetics of the adapter-virus complex, we sought to incorporate the CXCL12 ligand directly into the adenovirus genome. We demonstrated the successful incorporation of the CXCL12 gene via PCR and confirmed CXCL12 protein expression using an ELISA binding assay (Figure 1(D)).

The infection efficiency of Ad5-ffCXCL12 was analyzed by treating the breast cancer cell lines at increasing MOI for 72 hours. In these studies, Ad5-ffCXCL12 consistently exhibited greater infection in breast cancer cells when compared with Ad5-wtFiber. Breast cancer cell lines MDA-MB-231 and MDA-MB-436 showed high levels of CXADR, and thus, Ad5-wtFiber infection was greater in these cell lines when compared with the other breast cancer cell lines. High levels of CXADR, however, were not sufficient for infectivity. Although the immortalized breast epithelial cell line (MCF-12A) exhibited high levels of CXADR, these cells were poorly infected with Ad5-wtFiber (Figure 3(A)), indicating that additional cellular components may be necessary to mediate wild-type adenovirus infection efficiently. In contrast, Ad5-ffCXCL12 infection was improved in MCF$12 \mathrm{~A}$ cells, likely due to the expression of CXCR7 at the cell surface.

The CXCR4-CXCR7-CXCL12 axis has been implicated in the initiation, progression, and metastasis of cancer cells. CXCL12 has been known as a specific ligand to the chemokine receptor, CXCR4 [24], for over two decades. In 2005, CXCR7 was also dis-covered to have a high binding affinity to CXCL12 [35]. Since then, the involvement of the CXCR4-CXCR7-CXCL12 axis in breast cancer has been extensively explored. CXCR4 has been shown to be over-expressed in a variety of cancers, including breast cancer [58]. Specifically, CXCR4 has been implicated in tumor cell survival and progression, epithelial-mesenchymal transition (EMT), trafficking of cancer cells [24], and metastasis [24] [28] [29]. CXCR7 also is overexpressed in a variety of cancers, including breast cancer [36]. It has been primarily considered a scavenger receptor for CXCL12 to manage extracellular CXCL12 levels and limit CXCL12-CXCR4 binding [59] [60]. It has also been implicated in the progression and metastasis of CXCR4-expressing tumor cells [60] [61]. In contrast, CXCR7 expression in breast cancer tumor vasculature has been shown to control and inhibit metastasis [33]. Despite the common consensus that CXCR7 acts as a sequestering receptor for CXCL12, recent evidence has been demonstrated that CXCL12-CXCR7 binding results in downstream signaling affecting cancer stem cell (CSC) survival and proliferation, as well as EMT [62] [63] and metastasis [36]. CXCR4 and CXCR7 have been found to be expressed either in separate populations of cells or co-expressed on the same cells within breast tumors [32] [36] [57] [64]. In addition to coexpression, both receptors have been observed to heterodimerize to mediate CXCR4 signaling [34] [65] [66]. 


\section{Conclusions}

In conclusion, this study showed an increased infection efficiency of a fibermodified adenovirus (Ad5-ffCXCL12) in breast cancer cells, primarily overexpressing CXCR7 and in HEK293 cells overexpressing CXCR4. In addition, Ad5ffCXCL12 oncolytic efficiency was similar to the Ad5-wtFiber control, suggesting that the modifications did not impair the virus's ability to replicate within the cell. We demonstrated a degree of specificity to the CXCR4 and CXCR7 receptors in an isogenic hamster cell line. However, the major limitations we observed in controlling infection in breast cancer cells are likely due to additional proteins on the cell surface that mediate viral infection, independent of the fiber. Further studies will be needed to assess the ability to simultaneously target the adenovirus to a specific receptor and block binding of hexon to extracellular receptors, such as heparan sulfate glycosaminoglycans.

Overall, we have developed Ad5-ffCXCL12 as a therapeutic oncolytic adenovirus candidate for breast cancer therapy that warrants further investigation. Future in vivo studies will be needed to assess this virus a replication-permissive immunocompetent animal model to characterize its oncolytic ability in an in vivo setting adequately. The most common animal models to be utilized in preclinical oncolytic adenovirus studies have been murine xenograft models. However, since murine models are not permissive to human Ad5 replication due to species-specificity, preclinical assessment of Ad5 vectors has been limited. Thus far, Syrian hamster and porcine species have emerged as replication-competent animal models for investigating oncolytic adenoviruses [67] [68] [69]. Nonetheless, a suitable breast cancer cell line overexpressing CXCR4 or CXCR7 must also be developed to utilize these in vivo models.

\section{Acknowledgements}

The authors would like to thank the research staff in the Department of Comparative Biomedical Science in the School of Veterinary Medicine at Louisiana State University for their technical assistance. An abstract describing unpublished work from the doctoral dissertation of Samia M. O’Bryan was published in the LSU Digital Commons repository [70].

\section{Funding}

This work was supported, in part, by National Institutes of Health grant 5R01CA154697 and seed project funding from the LSU School of Veterinary Medicine.

\section{Conflicts of Interest}

The authors declare no conflict of interest. The funders had no role in the design of the study, in the collection, analyses, or interpretation of data, in the writing of the manuscript, or in the decision to publish the results. 


\section{References}

[1] Siegel, R.L., Miller, K.D. and Jemal, A. (2019) Cancer Statistics, 2019. CA: A Cancer Journal for Clinicians, 69, 7-34. https://doi.org/10.3322/caac.21551

[2] O’Bryan, S.M. and Mathis, J.M. (2018) Oncolytic Virotherapy for Breast Cancer Treatment. Current Gene Therapy, 18, 192-205. https://doi.org/10.2174/1566523218666180910163805

[3] Aghi, M. and Martuza, R.L. (2005) Oncolytic Viral Therapies-The Clinical Experience. Oncogene, 24, 7802-7816. https://doi.org/10.1038/sj.onc.1209037

[4] Alemany, R., Balagué, C. and Curiel, D.T. (2000) Replicative Adenoviruses for Cancer Therapy. Nature Biotechnology, 18, 723-727. https://doi.org/10.1038/77283

[5] Alemany, R. (2014) Oncolytic Adenoviruses in Cancer Treatment. Biomedicines, 2, 36-49. https://doi.org/10.3390/biomedicines2010036

[6] Dong, X., Qu, W., Ma, S., Zhu, Z., Zheng, C., He, A., Karlsson, A., Xu, K. and Zheng, X. (2013) Potent Antitumoral Effects of Targeted Promoter-Driven Oncolytic Adenovirus Armed with $D m-d N K$ for Breast Cancer in vitro and in vivo. Cancer Letters, 328, 95-103. https://doi.org/10.1016/j.canlet.2012.09.003

[7] Zhu, W., Zhang, H., Shi, Y., Song, M., Zhu, B. and Wei, L. (2013) Oncolytic Adenovirus Encoding Tumor Necrosis Factor-Related Apoptosis Inducing Ligand (TRAIL) Inhibits the Growth and Metastasis of Triple-Negative Breast Cancer. Cancer Biology and Therapy, 14, 1016-1023. https://doi.org/10.4161/cbt.26043

[8] Hu, Z., Zhang, Z., Guise, T. and Seth, P. (2010) Systemic Delivery of an Oncolytic Adenovirus Expressing Soluble Transforming Growth Factor-Beta Receptor II-Fc Fusion Protein Can Inhibit Breast Cancer Bone Metastasis in a Mouse Model. Human Gene Therapy, 21, 1623-1629. https://doi.org/10.1089/hum.2010.018

[9] Cody, J., Rivera, A.A., Lyons, G., Yang, S., Wang, M., Sarver, D., Wang, D., Selander, K., Kuo, H.-C., Meleth, S., Feng, X., Siegall, G. and Douglas, J. (2010) Arming a Replicating Adenovirus with Osteoprotegerin Reduces the Tumor Burden in a Murine Model of Osteolytic Bone Metastases of Breast Cancer. Cancer Gene Therapy, 17, 893-905. https://doi.org/10.1038/cgt.2010.47

[10] Fang, L., Cheng, Q., Bai, J., Qi, Y.-D., Liu, J.-J., Li, L.-T. and Zheng, J.-N. (2013) An Oncolytic Adenovirus Expressing Interleukin-24 Enhances Antitumor Activities in Combination with Paclitaxel in Breast Cancer Cells. Molecular Medicine Reports, 8 , 1416-1424. https://doi.org/10.3892/mmr.2013.1680

[11] Xu, W., Yang, Y., Hu, Z., Head, M., Mangold, K.A., Sullivan, M., Wang, E., Saha, P., Gulukota, K., Helseth, D.L., Guise, T., Prabhkar, B.S., Kaul, K., Schreiber, H. and Seth, P. (2020) LyP-1-Modified Oncolytic Adenoviruses Targeting Transforming Growth Factor Beta Inhibit Tumor Growth and Metastases and Augment Immune Checkpoint Inhibitor Therapy in Breast Cancer Mouse Models. Human Gene Therapy, 31, 863-880. https://doi.org/10.1089/hum.2020.078

[12] Ranki, T., Särkioja, M., Hakkarainen, T., von Smitten, K., Kanerva, A. and Hemminki, A. (2007) Systemic Efficacy of Oncolytic Adenoviruses in Imagable Orthotopic Models of Hormone Refractory Metastatic Breast Cancer. International Journal of Cancer, 121, 165-174. https://doi.org/10.1002/ijc.22627

[13] Bauerschmitz, G.J., Ranki, T., Kangasniemi, L., Ribacka, C., Eriksson, M., Porten, M., Herrmann, I., Ristimäki, A., Virkkunen, P., Tarkkanen, M., Hakkarainen, T., Kanerva, A., Rein, D., Pesonen, S. and Hemminki, A. (2008) Tissue-Specific Promoters Active in $\mathrm{CD} 44^{+} \mathrm{CD} 24^{-/ \text {Low }}$ Breast Cancer Cells. Cancer Research, 68, 55335539. https://doi.org/10.1158/0008-5472.CAN-07-5288

[14] MacLeod, S.H., Elgadi, M.M., Bossi, G., Sankar, U., Pisio, A., Agopsowicz, K., Sha- 
ron, D., Graham, F.L. and Hitt, M.M. (2012) HER3 Targeting of Adenovirus by Fiber Modification Increases Infection of Breast Cancer Cells in Vitro, But Not following Intratumoral Injection in Mice. Cancer Gene Therapy, 19, 888-898. https://doi.org/10.1038/cgt.2012.79

[15] Platonov, M.E., Borovjagin, A.V., Kaverina, N., Xiao, T., Kadagidze, Z., Lesniak, M., Baryshnikova, M. and Ulasov, I.V. (2018) KISS1 Tumor Suppressor Restricts Angiogenesis of Breast Cancer Brain Metastases and Sensitizes Them to Oncolytic Virotherapy in Vitro. Cancer Letters, 417, 75-88.

https://doi.org/10.1016/j.canlet.2017.12.024

[16] Garza-Morales, R., Gonzalez-Ramos, R., Chiba, A., de Oca-Luna, R., McNally, L.R., McMasters, K.M. and Gomez-Gutierrez, J.G. (2018) Temozolomide Enhances TripleNegative Breast Cancer Virotherapy in Vitro. Cancers, 10, 144. https://doi.org/10.3390/cancers10050144

[17] Liikanen, I., Tahtinen, S., Guse, K., Gutmann, T., Savola, P., Oksanen, M., Kanerva, A. and Hemminki, A. (2016) Oncolytic Adenovirus Expressing Monoclonal Antibody Trastuzumab for Treatment of HER2-Positive Cancer. Molecular Cancer Therapeutics, 15, 2259-2269. https://doi.org/10.1158/1535-7163.MCT-15-0819

[18] Zhang, Z., Krimmel, J., Zhang, Z., Hu, Z. and Seth, P. (2011) Systemic Delivery of a Novel Liver-Detargeted Oncolytic Adenovirus Causes Reduced Liver Toxicity but Maintains the Antitumor Response in a Breast Cancer Bone Metastasis Model. $\mathrm{Hu}$ man Gene Therapy, 22, 1137-1142. https://doi.org/10.1089/hum.2011.003

[19] Kim, M., Zinn, K.R., Barnett, B.G., Sumerel, L.A., Krasnykh, V., Curiel, D.T. and Douglas, J.T. (2002) The Therapeutic Efficacy of Adenoviral Vectors for Cancer Gene Therapy Is Limited by a Low Level of Primary Adenovirus Receptors on Tumour Cells. European Journal of Cancer, 38, 1917-1926. https://doi.org/10.1016/S0959-8049(02)00131-4

[20] Sirena, D., Lilienfeld, B., Eisenhut, M., Kälin, S., Boucke, K., Beerli, R.R., Vogt, L., Ruedl, C., Bachmann, M.F., Greber, U.F. and Hemmi, S. (2004) The Human Membrane Cofactor CD46 Is a Receptor for Species B Adenovirus Serotype 3. Journal of Virology, 78, 4454-4462. https://doi.org/10.1128/JVI.78.9.4454-4462.2004

[21] Koski, A., Kangasniemi, L., Escutenaire, S., Pesonen, S., Cerullo, V., Diaconu, I., Nokisalmi, P., Raki, M., Rajecki, M., Guse, K., Ranki, T., Oksanen, M., Holm, S.-L., Haavisto, E., Karioja-Kallio, A., Laasonen, L., Partanen, K., Ugolini, M., Helminen, A., Karli, E., Hannuksela, P., Pesonen, S., Joensuu, T., Kanerva, A. and Hemminki, A. (2010) Treatment of Cancer Patients with a Serotype 5/3 Chimeric Oncolytic Adenovirus Expressing GMCSF. Molecular Therapy, 18, 1874-1884.

https://doi.org/10.1038/mt.2010.161

[22] Pesonen, S., Diaconu, I., Cerullo, V., Escutenaire, S., Raki, M., Kangasniemi, L., Nokisalmi, P., Dotti, G., Guse, K., Laasonen, L., Partanen, K., Karli, E., Haavisto, E., Oksanen, M., Karioja-Kallio, A., Hannuksela, P., Holm, S.L., Kauppinen, S., Joensuu, T., Kanerva, A. and Hemminki, A. (2012) Integrin Targeted Oncolytic Adenoviruses Ad5-D24-RGD and Ad5-RGD-D24-GMCSF for Treatment of Patients with Advanced Chemotherapy Refractory Solid Tumors. International Journal of Cancer, 130, 1937-1947. https://doi.org/10.1002/ijc.26216

[23] Ranki, T., Kanerva, A., Ristimäki, A., Hakkarainen, T., Särkioja, M., Kangasniemi, L., Raki, M., Laakkonen, P., Goodison, S. and Hemminki, A. (2007) A Heparan Sulfate-Targeted Conditionally Replicative Adenovirus, Ad5.pk7- $\Delta 24$, for the Treatment of Advanced Breast Cancer. Gene Therapy, 14, 58-67.

https://doi.org/10.1038/sj.gt.3302830

[24] Müller, A., Homey, B., Soto, H., Ge, N., Catron, D., Buchanan, M.E., McClanahan, 
T., Murphy, E., Yuan, W., Wagner, S.N., Barrera, J., Mohar, A., Verástegui, E. and Zlotnik, A. (2001) Involvement of Chemokine Receptors in Breast Cancer Metastasis. Nature, 410, 50-56. https://doi.org/10.1038/35065016

[25] Balkwill, F. (2004) The Significance of Cancer Cell Expression of the Chemokine Receptor CXCR4. Seminars in Cancer Biology, 14, 171-179.

https://doi.org/10.1016/j.semcancer.2003.10.003

[26] Bleul, C.C., Farzan, M., Choe, H., Parolin, C., Clark-Lewis, I., Sodroski, J. and Springer, T.A. (1996) The Lymphocyte Chemoattractant SDF-1 Is a Ligand for LESTR/ Fusin and Blocks HIV-1 Entry. Nature, 382, 829-833.

https://doi.org/10.1038/382829a0

[27] Guo, F., Wang, Y., Liu, J., Mok, S.C., Xue, F. and Zhang, W. (2016) CXCL12/ CXCR4: A Symbiotic Bridge Linking Cancer Cells and Their Stromal Neighbors in Oncogenic Communication Networks. Oncogene, 35, 816-826.

https://doi.org/10.1038/onc.2015.139

[28] Hung, C.-S., Su, H.-Y., Liang, H.-H., Lai, C.-W., Chang, Y.-C., Ho, Y.-S., Wu, C.-H., Ho, J.-D., Wei, P.-L. and Chang, Y.-J. (2014) High-Level Expression of CXCR4 in Breast Cancer Is Associated with Early Distant and Bone Metastases. Tumor Biology, 35, 1581-1588. https://doi.org/10.1007/s13277-013-1218-9

[29] Kang, H., Watkins, G., Douglas-Jones, A., Mansel, R.E. and Jiang, W.G. (2005) The Elevated Level of CXCR4 Is Correlated with Nodal Metastasis of Human Breast Cancer. The Breast, 14, 360-367. https://doi.org/10.1016/j.breast.2004.12.007

[30] Wendel, C., Hemping-Bovenkerk, A., Krasnyanska, J., Mees, S., Kochetkova, M., Stoeppeler, S. and Haier, J. (2012) CXCR4/CXCL12 Participate in Extravasation of Metastasizing Breast Cancer Cells within the Liver in a Rat Model. PLoS ONE, 7, e30046. https://doi.org/10.1371/journal.pone.0030046

[31] Balabanian, K., Lagane, B., Infantino, S., Chow, K.Y.C., Harriague, J., Moepps, B., Arenzana-Seisdedos, F., Thelen, M. and Bachelerie, F. (2005) The Chemokine SDF-1/ CXCL12 Binds to and Signals through the Orphan Receptor RDC1 in T Lymphocytes. Journal of Biological Chemistry, 280, 35760-35766. https://doi.org/10.1074/jbc.M508234200

[32] Luker, K.E., Lewin, S.A., Mihalko, L.A., Schmidt, B.T., Winkler, J.S., Coggins, N.L., Thomas, D.G. and Luker, G.D. (2012) Scavenging of CXCL12 by CXCR7 Promotes Tumor Growth and Metastasis of CXCR4-Positive Breast Cancer Cells. Oncogene, 31, 4750-4758. https://doi.org/10.1038/onc.2011.633

[33] Stacer, A.C., Fenner, J., Cavnar, S.P., Xiao, A., Zhao, S., Chang, S.L., Salomonnson, A., Luker, K.E. and Luker, G.D. (2016) Endothelial CXCR7 Regulates Breast Cancer Metastasis. Oncogene, 35, 1716-1724. https://doi.org/10.1038/onc.2015.236

[34] Hattermann, K., Holzenburg, E., Hans, F., Lucius, R., Held-Feindt, J. and Mentlein, R. (2014) Effects of the Chemokine CXCL12 and Combined Internalization of Its Receptors CXCR4 and CXCR7 in Human MCF-7 Breast Cancer Cells. Cell and Tissue Research, 357, 253-266. https://doi.org/10.1007/s00441-014-1823-y

[35] Burns, J.M., Summers, B.C., Wang, Y., Melikian, A., Berahovich, R., Miao, Z., Penfold, M.E.T., Sunshine, M., Littman, D.R., Kuo, C.J., Wei, K., McMaster, B.E., Wright, K., Howard, M.C. and Schall, T.J. (2006) A Novel Chemokine Receptor for SDF-1 and I-TAC Involved in Cell Survival, Cell Adhesion, and Tumor Development. Journal of Experimental Medicine, 203, 2201-2213.

https://doi.org/10.1084/jem.20052144

[36] Miao, Z., Luker, K.E., Summers, B.C., Berahovich, R., Bhojani, M.S., Rehemtulla, A., Kleer, C.G., Essner, J.J., Nasevicius, A., Luker, G.D., Howard, M.C. and Schall, T.J. 
(2007) CXCR7 (RDC1) Promotes Breast and Lung Tumor Growth in vivo and Is Expressed on Tumor-Associated Vasculature. Proceedings of the National Academy of Sciences of the United States of America, 104, 15735-15740. https://doi.org/10.1073/pnas.0610444104

[37] Bhatia, S., O’Bryan, S.M., Rivera, A.A., Curiel, D.T. and Mathis, J.M. (2016) CXCL12 Retargeting of an Adenovirus Vector to Cancer Cells Using a Bispecific Adapter. Oncolytic Virotherapy, 5, 99-113. https://doi.org/10.2147/OV.S112107

[38] Verheije, M.H. and Rottier, P.J. (2012) Retargeting of Viruses to Generate Oncolytic Agents. Advances in Virology, 2012, Article ID: 798526. https://doi.org/10.1155/2012/798526

[39] Smith, S.E., Mellor, P., Ward, A.K., Kendall, S., McDonald, M., Vizeacoumar, F.S., Vizeacoumar, F.J., Napper, S. and Anderson, D.H. (2017) Molecular Characterization of Breast Cancer Cell Lines through Multiple Omic Approaches. Breast Cancer Research, 19, Article No. 65. https://doi.org/10.1186/s13058-017-0855-0

[40] Farkas, T., Yang, K., Le Pendu, J., Baines, J.D. and Cardin, R.D. (2019) The Coxsackievirus and Adenovirus Receptor, a Required Host Factor for Recovirus Infection, Is a Putative Enteric Calicivirus Receptor. Journal of Virology, 93, e00869-19. https://doi.org/10.1128/JVI.00869-19

[41] Belousova, N., Korokhov, N., Krendelshchikova, V., Simonenko, V., Mikheeva, G., Triozzi, P.L., Aldrich, W.A., Banerjee, P.T., Gillies, S.D., Curiel, D.T. and Krasnykh, V. (2003) Genetically Targeted Adenovirus Vector Directed to CD40-Expressing Cells. Journal of Virology, 77, 11367-11377. https://doi.org/10.1128/JVI.77.21.11367-11377.2003

[42] Krasnykh, V., Belousova, N., Korokhov, N., Mikheeva, G. and Curiel, D.T. (2001) Genetic Targeting of an Adenovirus Vector via Replacement of the Fiber Protein with the Phage T4 Fibritin. Journal of Virology, 75, 4176-4183. https://doi.org/10.1128/JVI.75.9.4176-4183.2001

[43] Kashentseva, E.A., Seki, T., Curiel, D.T. and Dmitriev, I.P. (2002) Adenovirus Targeting to $c-e r b B-2$ Oncoprotein by Single-Chain Antibody Fused to Trimeric Form of Adenovirus Receptor Ectodomain. Cancer Research, 62, 609-616.

[44] He, T.-C., Zhou, S., da Costa, L., Yu, J., Kinzler, K. and Vogelstein, B. (1998) A Simplified System for Generating Recombinant Adenoviruses. Proceedings of the National Academy of Sciences of the United States of America, 95, 2509-2514. https://doi.org/10.1073/pnas.95.5.2509

[45] Reeh, M., Bockhorn, M., Görgens, D., Vieth, M., Hoffmann, T., Simon, R., Izbicki, J.R., Sauter, G., Schumacher, U. and Anders, M. (2013) Presence of the Coxsackievirus and Adenovirus Receptor (CAR) in Human Neoplasms: A Multitumour Array Analysis. British Journal of Cancer, 109, 1848-1858.

https://doi.org/10.1038/bjc.2013.509

[46] Papanikolopoulou, K., Forge, V., Goeltz, P. and Mitraki, A. (2004) Formation of Highly Stable Chimeric Trimers by Fusion of an Adenovirus Fiber Shaft Fragment with the Foldon Domain of Bacteriophage T4 Fibritin. Journal of Biological Chemistry, 279, 8991-8998. https://doi.org/10.1074/jbc.M311791200

[47] van Erp, E., Kaliberova, L., Kaliberov, S. and Curiel, D.T. (2015) Retargeted Oncolytic Adenovirus Displaying a Single Variable Domain of Camelid Heavy-ChainOnly Antibody in a Fiber Protein. Molecular Therapy Oncolytics, 2, 15001. https://doi.org/10.1038/mto.2015.1

[48] Sakr, H.I., Coleman, D.T., Cardelli, J.A. and Mathis, J.M. (2015) Characterization of an Oncolytic Adenovirus Vector Constructed to Target the cMet Receptor. Onco- 
lytic Virotherapy, 4, 119-132. https://doi.org/10.2147/OV.S87369

[49] Stasiak, A.C. and Stehle, T. (2020) Human Adenovirus Binding to Host Cell Receptors: A Structural View. Medical Microbiology and Immunology, 209, 325-333. https://doi.org/10.1007/s00430-019-00645-2

[50] Dechecchi, M.C., Melotti, P., Bonizzato, A., Santacatterina, M., Chilosi, M. and Cabrini, G. (2001) Heparan Sulfate Glycosaminoglycans Are Receptors Sufficient to Mediate the Initial Binding of Adenovirus Types 2 and 5. Journal of Virology, 75, 8772-8780. https://doi.org/10.1128/JVI.75.18.8772-8780.2001

[51] Bayo-Puxan, N., Cascallo, M., Gros, A., Huch, M., Fillat, C. and Alemany, R. (2006) Role of the Putative Heparan Sulfate Glycosaminoglycan-Binding Site of the Adenovirus Type 5 Fiber Shaft on Liver Detargeting and Knob-Mediated Retargeting. Journal of General Virology, 87, 2487-2495. https://doi.org/10.1099/vir.0.81889-0

[52] Lyle, C. and McCormick, F. (2010) Integrin $\alpha v \beta 5$ Is a Primary Receptor for Adenovirus in CAR-Negative Cells. Virology Journal, 7, Article No. 148. https://doi.org/10.1186/1743-422X-7-148

[53] Wang, B., Guo, P. and Auguste, D.T. (2015) Mapping the CXCR4 Receptor on Breast Cancer Cells. Biomaterials, 57, 161-168. https://doi.org/10.1016/j.biomaterials.2015.04.023

[54] Sivrikoz, O.N, Doganay, L., Sivrikoz, U.K, Karaarslan, S. and Sanal, S.M. (2013) Distribution of CXCR4 and $\gamma$-Catenin Expression Pattern in Breast Cancer Subtypes and Their Relationship to Axillary Nodal Involvement. Polish Journal of Pathology, 64, 253-259. https://doi.org/10.5114/pjp.2013.39333

[55] Zhang, M., Liu, H.X., Teng, X.D., Wang, H., Cui, J., Jia, S., Gu, X. and Li, Z. (2012) The Differences in CXCR4 Protein Expression Are Significant for the Five Molecular Subtypes of Breast Cancer. Ultrastructural Pathology, 36, 381-386. https://doi.org/10.3109/01913123.2012.728687

[56] Chen, H.W., Du, C.W., Wei, X., Khoo, U.S. and Zhang, G. (2013) Cytoplasmic CXCR4 High-Expression Exhibits Distinct Poor Clinicopathological Characteristics and Predicts Poor Prognosis in Triple-Negative Breast Cancer. Current Molecular Medicine, 13, 410-416. https://doi.org/10.2174/156652413805076803

[57] Wu, W., Qian, L., Chen, X. and Ding, B. (2015) Prognostic Significance of CXCL12, CXCR4, and CXCR7 in Patients with Breast Cancer. International Journal of Clinical and Experimental Pathology, 8, 13217-13224.

[58] Zlotnik, A. (2006) Chemokines and Cancer. International Journal of Cancer, 119, 2026-2029. https://doi.org/10.1002/ijc.22024

[59] Boldajipour, B., Mahabaleshwar, S., Kardash, E., Reichman-Fried, M., Blaser, H., Minina, S., Wilson, D., Xu, Q. and Raz, E. (2008) Control of Chemokine-Guided Cell Migration by Ligand Sequestration. Cell, 132, 463-473. https://doi.org/10.1016/j.cell.2007.12.034

[60] Luker, K.E., Steele, J.M., Mihalko, L.A., Ray, P. and Luker, G.D. (2010) Constitutive and Chemokine-Dependent Internalization and Recycling of CXCR7 in Breast Cancer Cells to Degrade Chemokine Ligands. Oncogene, 29, 4599-4610. https://doi.org/10.1038/onc.2010.212

[61] Salazar, N., Munoz, D., Kallifatidis, G., Singh, R., Jorda, M. and Lokeshwar, B.L. (2014) The Chemokine Receptor CXCR7 Interacts with EGFR to Promote Breast Cancer Cell Proliferation. Molecular Cancer, 13, Article No. 198. https://doi.org/10.1186/1476-4598-13-198

[62] Tang, X., Li, X., Li, Z., Liu, Y., Yao, L., Song, S., Yang, H. and Li, C. (2016) Downregulation of CXCR7 Inhibits Proliferative Capacity and Stem Cell-Like Properties 
in Breast Cancer Stem Cells. Tumor Biology, 37, 13425-13433.

https://doi.org/10.1007/s13277-016-5180-1

[63] Wu, Y.-C., Tang, S.-H., Sung, G.-H. and Sun, K.-H. (2016) CXCR7 Mediates TGFbeta1-Promoted EMT and Tumor-Initiating Features in Lung Cancer. Oncogene, 35, 2123-2132. https://doi.org/10.1038/onc.2015.274

[64] Heinrich, E.L., Lee, W., Lu, J., Lowy, A.M. and Kim, J. (2012) Chemokine CXCL12 Activates Dual CXCR4 and CXCR7-Mediated Signaling Pathways in Pancreatic Cancer Cells. Journal of Translational Medicine, 10, Article No. 68. https://doi.org/10.1186/1479-5876-10-68

[65] Levoye, A., Balabanian, K., Baleux, F., Bachelerie, F. and Lagane, B. (2009) CXCR7 Heterodimerizes with CXCR4 and Regulates CXCL12-Mediated G Protein Signaling. Blood, 113, 6085-6093. https://doi.org/10.1182/blood-2008-12-196618

[66] Décaillot, F.M., Kazmi, M.A., Lin, Y., Ray-Saha, S., Sakmar, T.P. and Sachdev, P. (2011) CXCR7/CXCR4 Heterodimer Constitutively Recruits $\beta$-Arrestin to Enhance Cell Migration. Journal of Biological Chemistry, 286, 32188-32197. https://doi.org/10.1074/jbc.M111.277038

[67] Koodie, L., Robertson, M.G., Chandrashekar, M., Ruth, G., Dunning, M., Bianco, R.W. and Davydova, J. (2019) Rodents versus Pig Model for Assessing the Performance of Serotype Chimeric Ad5/3 Oncolytic Adenoviruses. Cancers, 11, 198. https://doi.org/10.3390/cancers 11020198

[68] Thomas, M.A., Spencer, J.F., Regina, M.C., Dhar, D., Tollefson, A.E., Toth, K. and Wold, W. (2006) Syrian Hamster as a Permissive Immunocompetent Animal Model for the Study of Oncolytic Adenovirus Vectors. Cancer Research, 66, 1270-1276. https://doi.org/10.1158/0008-5472.CAN-05-3497

[69] Wold, W. and Toth, K. (2012) Chapter Three-Syrian Hamster as an Animal Model to Study Oncolytic Adenoviruses and to Evaluate the Efficacy of Antiviral Compounds. In: David, T.C. and Paul, B.F. Eds., Advance in Cancer Research, Vol. 115, Elsevier, Amsterdam, 69-92. https://doi.org/10.1016/B978-0-12-398342-8.00003-3

[70] O’Bryan, S.M. (2019) Generation of an Oncolytic Adenovirus Targeting the CXCR4 and CXCR7 Chemokine Receptors in Breast Cancer. LSU Doctoral Dissertations, 5035, Louisiana State University and Agricultural and Mechanical College, Baton Rouge. https://digitalcommons.lsu.edu/gradschool dissertations/5035 